Journal of Advanced Research in Fluid Mechanics and Thermal Sciences

\title{
Effects of Coffee Form and Distributor Hole Angle on The Fluidization Behavior and Specific Energy Consumption in The Fluidized Bed Machine
}

\author{
Thatchapol Chungcharoen ${ }^{1}$, Warunee Limmun ${ }^{1}$, Sansanee Sansiribhan ${ }^{2, *}$ \\ 1 Engineering Department, King Mongkut's Institute of Technology Ladkrabang, Prince of Chumphon Campus, Chumphon, Thailand \\ 2 Applied Physics Program, Faculty of Science and Technology, Suan Sunandha Rajabhat University, Bangkok, 10300, Thailand
}

\begin{tabular}{|c|c|}
\hline ARTICLE INFO & ABSTRACT \\
\hline Article history: & The fluidized bed technique was applied to use with the Robusta coffee in this research. \\
\hline Received 23 April 2021 & fluidization behavior and specific energy consumption were investigated under various \\
\hline Received in revised form 23 June 2021 & coffee forms and distributor hole angles. Moreover, the minimum fluidization velocity \\
\hline Accepted 25 June 2021 & (Vmf) was also determined. Experiments are carried out in a sample bed height of $5 \mathrm{~cm}$ \\
\hline Available online 23 July 2021 & $\begin{array}{l}\text { with ambience air. In this study, two coffee forms (Ripe coffee cherries; RCC and } \\
\text { parchment coffee; PC) and three distributor hole angles }\left(45^{\circ}, 60^{\circ} \text { and } 90^{\circ} \text { ) are }\right. \\
\text { examined. The experimental result shown that the fluidization behavior is influenced }\end{array}$ \\
\hline Keywords: & by coffee form and distributor hole angle. The RCC and distributor hole angle of $60^{\circ}$ \\
\hline Coffee form; Distributor hole angle; & provided the low pressure drop throughout the superficial air velocity. The low values \\
\hline Fluidization behavior & of $\mathrm{Vmf}$ and SEC were also achieved in the RCC and distributor hole angle of $60^{\circ}$. \\
\hline
\end{tabular}

\section{Introduction}

Coffee is one of most popular agricultural crops in Chumphon province especially Robusta coffee which represents around $80 \%$ of the total Thailand coffee production [1]. Normally, the Robusta coffee is produced to green coffee bean by either dry or wet processing [2,3]. The drying is one of important steps in those processing. It is done by placing the ripe coffee cherries (in case of dry processing) or the parchment coffees (in case of wet processing) in the sun until the moisture content reached $11-12 \%$ wet basis [4]. This drying method provides the long drying time because it depends on the weather conditions. Moreover, it can't control the uniform moisture content during drying. Therefore, the new method for drying is necessarily determined.

In recent years, the fluidized bed drying technique have been applied to dry many agricultural crops [5-7]. This technique provides the good mixing between material and drying medium, leading to rapidly decrease the moisture content and resulting in the shorter drying time [8]. Moreover, it provides the uniform moisture content during drying. By this drying method, it would be more effective to reduce the moisture content of coffee. The flow characteristic is one of the most important concerns in fluid and there are some studies on the flow characteristic $[9,10]$. For fluidized

\footnotetext{
* Corresponding author.

E-mail address: sansanee.sa@ssru.ac.th

https://doi.org/10.37934/arfmts.84.2.152158
} 
bed drying technique, fluidization behavior is focused because it is used for investigation in the minimum fluidization velocity (Umf) which directly effects the decrease of moisture content. There are many factors affecting the Umf and several investigations have been done in the Umf. Escudero and Heindel [11] studied the Umf in a 3D fluidized bed modified with an acoustic field. Their results revealed that as the frequency and sound pressure level increased, the value of Umf decreased. Khan et al., [12] studied the effect of initial static bed height and liquid superficial velocity on the Umf value and pressure drop for the bed of semolina particles in liquid-solid fluidization. The results showed that there was no significant change in the Umf with different initial static bed height. The increase of liquid superficial velocity above the Umf led the particles vigorous motion and resulted in the better mixing in the fluidization. Sau et al., [13] studied the Umf and the pressure drop across the bed using a gas-solid conical tapered fluidized bed. The results showed that the Umf value was independent of bed height for this type of conical tapered fluidized bed. Zhang et al., [14] analyzed the effect of mechanical vibration on the fluidization characteristics of fly ash in a fluidized. The results showed that the mechanical vibration provided the decrease of Umf.

The coffee form and distributor hole angle are two interested factors which affected the Umf and it has not been reported about theirs factors effected on the Umf. Therefore, the main objective of this research was to investigate the effects of coffee form and distributor hole angle on the fluidization behavior in the fluidized bed dryer. Moreover, the specific energy consumption was also determined. The result of this research would be useful information for drying the coffee using the fluidized bed dryer.

\section{Methodology}

\subsection{Sample Preparation}

Ripe coffee cherries (RCC) as shown in Figure 1(a) were purchased from the Small and Medium Enterprises (SMEs) in Chumphon province. They were cleaned to get rid of foreign materials before testing. In term of parchment coffee (PC), the RCC was dehusked to the PC as Shown in Figure 1(b) before testing. The initial moisture contents of RCC and PC were found to be $60 \%$ (d.b.).

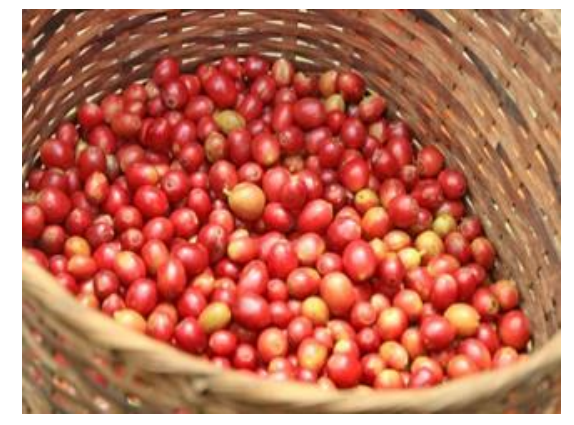

(a)

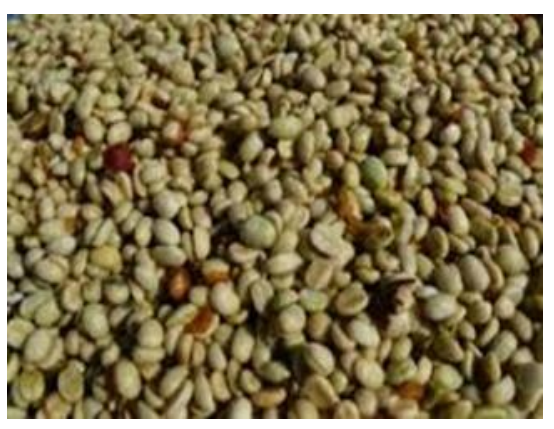

(b)

Fig. 1. Coffee form (a) Ripe coffee cherries (RCC) (b) parchment coffee (PC)

\subsection{Experimental Procedure}

The experiments were conducted in an air flow fluidized bed machine as shown in Figure 2. The cylindrical fluidized bed chamber was fabricated with acrylic of $20 \mathrm{~cm}$ diameter and $100 \mathrm{~cm}$ height. A blower of $2 \mathrm{hp}$ is used to generate the ambience air which entered into the chamber from bottom through distributor. As shown in Figure 3, there are three patterns of distributor based on distributor 
hole angle such as $45^{\circ}, 60^{\circ}$ and $90^{\circ}$. Inverter is used to control the flow of air and manometer is used to measure the pressure drop across the bed.

In each experiment, the samples (bed height $=5 \mathrm{~cm}$ ), both RCC and PC, were placed into a cylindrical fluidized bed chamber and the blower was started to fill the ambience air at various superficial air velocities. The pressure drop was observed in manometer. Moreover, the total amount of energy consumed during testing was also noted.

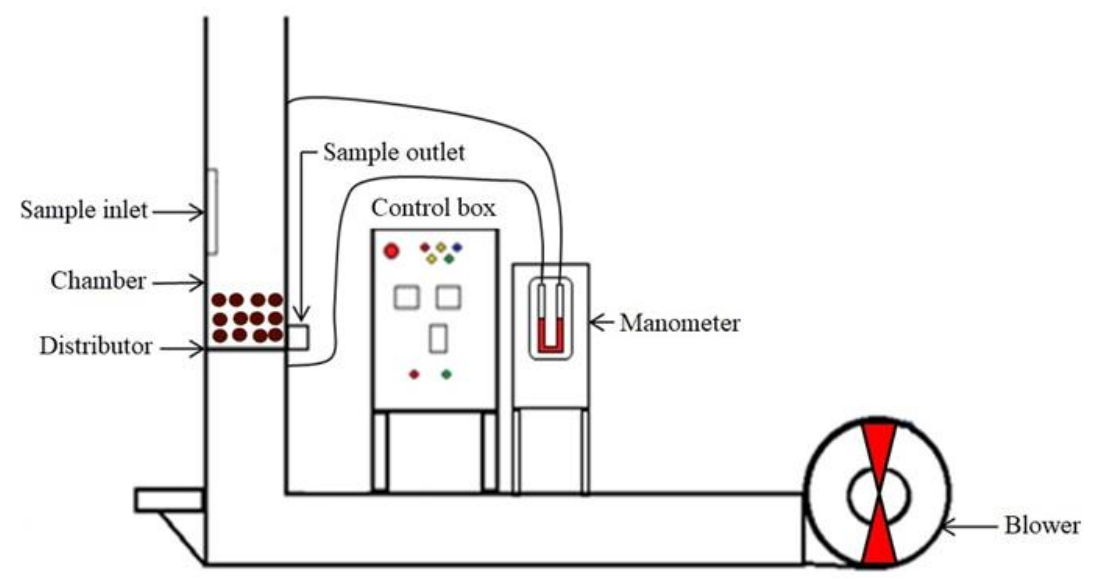

Fig. 2. Air flow fluidized bed machine

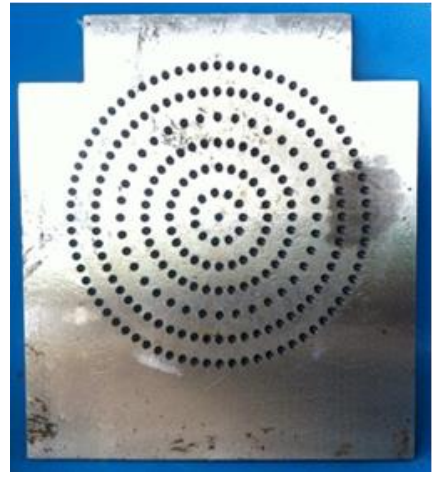

(a)

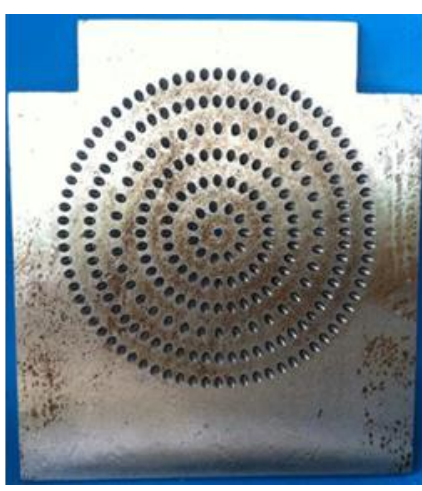

(b)

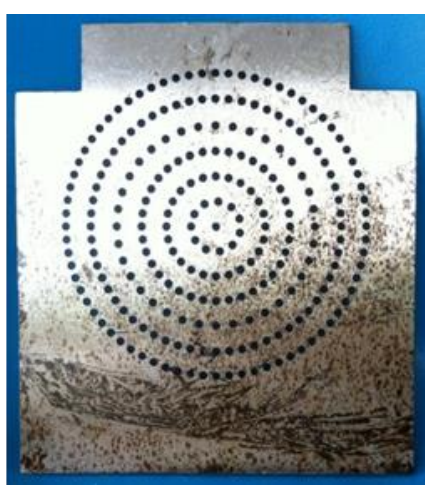

(c)

Fig. 3. patterns of distributor with different hole angle (a) hole angle of $45^{\circ}$ (b) hole angle of $60^{\circ}$ (c) hole angle of $90^{\circ}$

The pressure drop and specific energy consumption (SEC) value were calculated as shown in Eq. (1) and Eq. (2), respectively.

$\Delta P=\rho g \Delta h$

where $\Delta P$ is pressure drop across the bed $(\mathrm{Pa}), \rho \rho$ is fluid density $\left(\mathrm{kg} / \mathrm{m}^{3}\right), g$ is acceleration due to gravity $\left(\mathrm{m} / \mathrm{s}^{2}\right)$ and $\Delta h$ is different height of liquid in manometer $(\mathrm{m})$.

$S E C=\frac{3.6 P}{\text { Mass of sample }}$

where $S E C$ is specific energy consumption $(\mathrm{kWh} / \mathrm{kg})$ and $P$ is the total amount of energy consumed during testing (kWh). 


\section{Results}

\subsection{Bed Sample Properties}

The properties of RCC and PC were showed in Table 1. The experimental result shown that there are significantly different for all properties between RCC and PC. The PC provided the lower porosity and equivalent diameter than RCC while the weight of PC was higher than that of RCC. The different properties between RCC and PC may be due to the shape of sample $[15,16]$. The shape of PC was quite oval, whereas that of PCC was round, thus allowing the sample of PC to be tightly pack and resulting in the lower porosity and higher weight.

Table 1

The properties of RCC and PC

\begin{tabular}{llll}
\hline Coffee form & $\begin{array}{l}\text { Weight (bed height of } 5 \mathrm{~cm}) \\
(\mathrm{kg})\end{array}$ & Porosity & $\begin{array}{l}\text { Equivalent diameter } \\
(\mathrm{mm})\end{array}$ \\
\hline $\mathrm{RCC}$ & $0.97 \pm 0.00^{\mathrm{b}}$ & $0.65 \pm 0.03^{\mathrm{a}}$ & $12.5 \pm 0.23^{\mathrm{a}}$ \\
$\mathrm{PC}$ & $0.99 \pm 0.01^{\mathrm{a}}$ & $0.55 \pm 0.29^{\mathrm{b}}$ & $5.11 \pm 0.35^{\mathrm{b}}$ \\
\hline $\mathrm{a}, \mathrm{b}$ Means in the same column with different superscripts are significantly difference $(\mathrm{p}<0.05)$
\end{tabular}

\subsection{Fluidization Behavior}

Figure 4 shows the fluidization behavior of sample at various distributor hole angles. The changes of pressure drop for both RCC and PC had a similar pattern. The pressure drop was rapidly increased with increasing at the early superficial air velocity period (from 0 to $4 \mathrm{~m} / \mathrm{s}$ approximately). This is because bed of sample still fixed. When the superficial air velocity was more increased, the pressure drop became constant. This indicated that the fluidizing was achieved $[12,17,18]$. When comparing among the distributor hole angle, the pressure drop of distributor hole angle of $60^{\circ}$ was slightly lower than another distributor hole angle for both RCC and PC. This may because the distributor hole angle of $60^{\circ}$ provided the air to easily pass through the bed of sample.

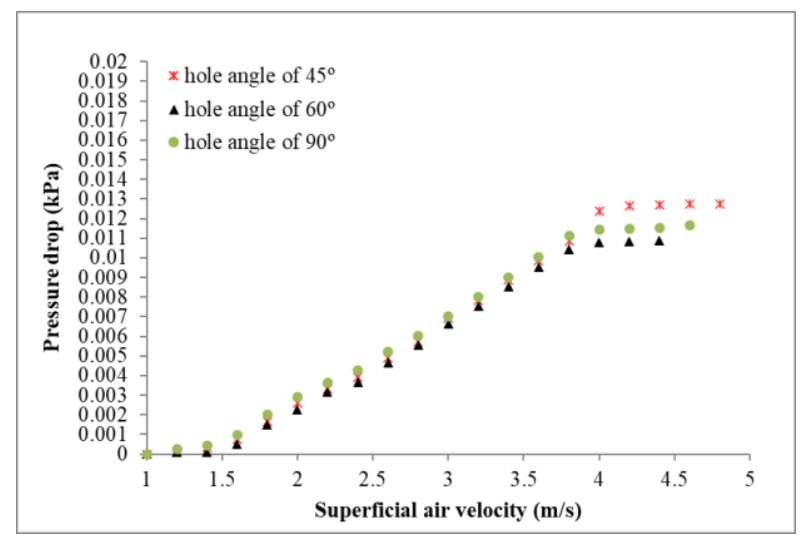

(a)

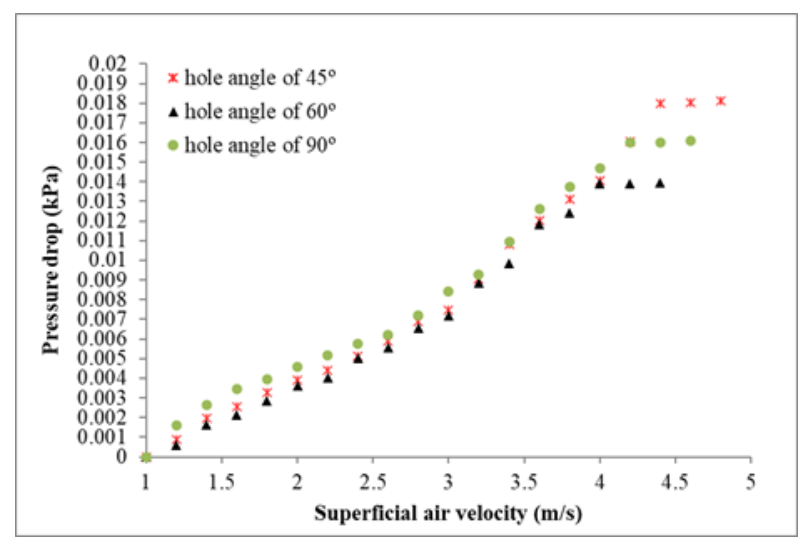

(b)

Fig. 4. Fluidization behavior of sample at various distributor hole angles (a) RCC (b) PC

The comparisons of fluidization behavior between RCC and PC at the same distributor hole angle were showed in Figure 5. The pressure drop of PC was higher than that of RCC for all distributor hole angle due to the cohesiveness of sample. The PC was the sticky particle, leading to more pressure drop than RCC. 


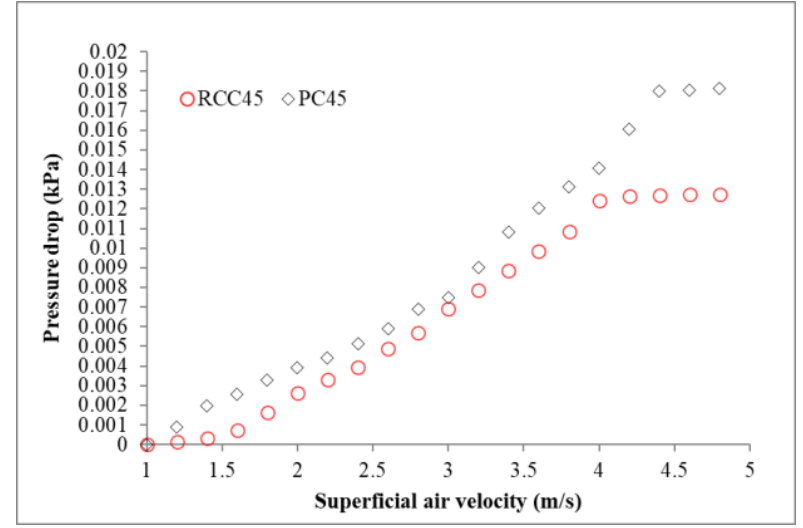

(a)

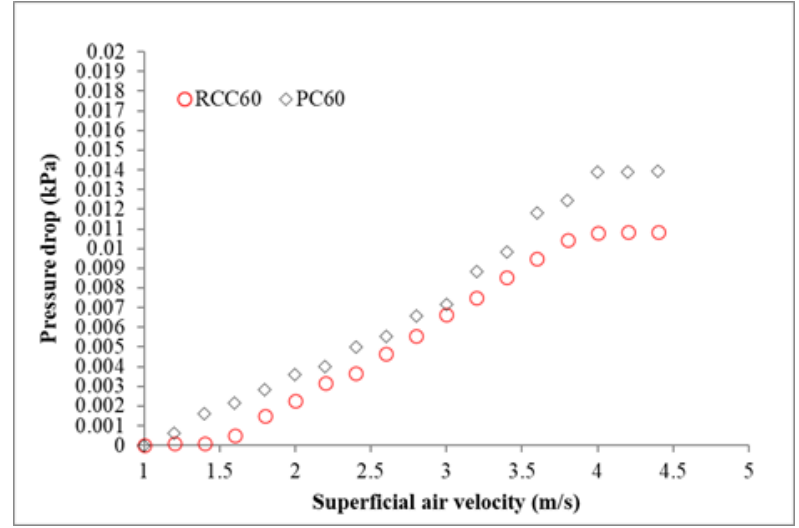

(b)

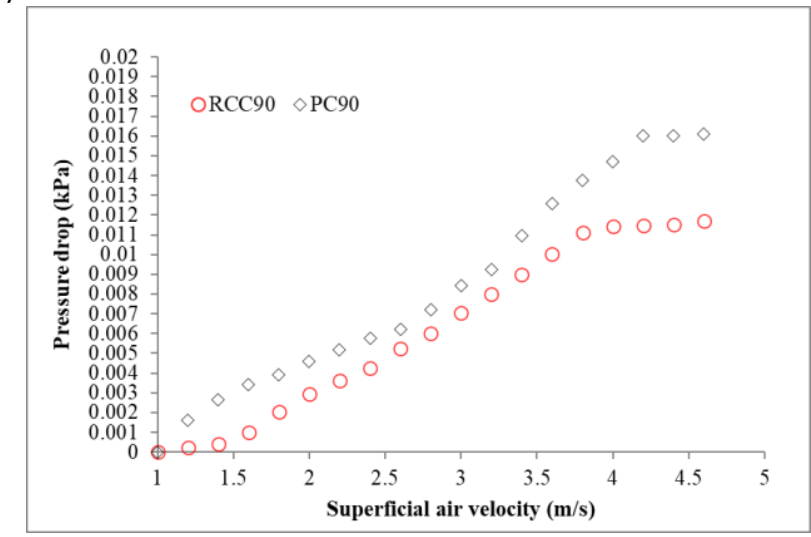

(c)

Fig. 5. Comparation of fluidization behavior between RCC and PC (a) distributor hole angle of $45^{\circ}$ (b) distributor hole angle of $60^{\circ}$ (c) distributor hole angle of $90^{\circ}$

\subsection{Minimum Fluidization Velocity (Vmf) and Specific Energy Consumption (SEC)}

The minimum fluidization velocity (Vmf) and specific energy consumption (SEC) of RCC and PC at various distributor hole angles were shown in Table 2. The experimental result shown that the coffee form and distributor hole angle affected the Vmf and SEC values. The RCC provided the lower Vmf than PC at every distributor hole angle. Moreover, the $\mathrm{Vmf}$ with distributor hole angle of $60^{\circ}$ was lowest for both RCC and PC. These led the lower SEC value in the RCC than PC and the lowest SEC value in distributor hole angle of $60^{\circ}$ when comparing with another distributor hole angle. The effect of distributor on the Vmf agrees with the results reported by Hilal et al., [19], who noted that the value of the minimum fluidization velocity was increased with decreasing perforated plate distributor hole pitch.

Table 2

The Vmf and SEC values of RCC and PC at various distributor hole angles

\begin{tabular}{llll}
\hline Coffee form & $\begin{array}{l}\text { Distributor hole } \\
\text { angle (Degree) }\end{array}$ & $\begin{array}{l}\text { Minimum fluidization } \\
\text { velocity }(\mathrm{m} / \mathrm{s})\end{array}$ & $\begin{array}{l}\text { SEC } \\
(\mathrm{kWh} / \mathrm{kg})\end{array}$ \\
\hline RCC & 45 & $4.2 \pm 0.0^{\mathrm{a}}$ & $6.73 \pm 0.14^{\mathrm{a}}$ \\
& 60 & $3.9 \pm 0.1^{\mathrm{b}}$ & $5.64 \pm 0.52^{\mathrm{b}}$ \\
& 90 & $4.1 \pm 0.1^{\mathrm{a}}$ & $6.75 \pm 0.77^{\mathrm{a}}$ \\
PC & 45 & $4.3 \pm 0.1^{\mathrm{a}}$ & $6.97 \pm 0.09^{\mathrm{a}}$ \\
& 60 & $4.0 \pm 0.0^{\mathrm{b}}$ & $5.81 \pm 0.24^{\mathrm{b}}$ \\
& 90 & $4.2 \pm 0.1^{\mathrm{a}}$ & $7.15 \pm 0.20^{\mathrm{a}}$ \\
\hline
\end{tabular}

$\mathrm{a}, \mathrm{b}$ Means in the same column with different superscripts are significantly difference $(p<0.05)$ 


\section{Conclusions}

In this study, the differences of coffee form (ripe coffee cherries: RCC and parchment coffee: PC) and distributor hole angle $\left(45^{\circ}, 60^{\circ}\right.$ and $\left.90^{\circ}\right)$ were performed to investigate the fluidization behavior and Specific Energy Consumption (SEC) in the Fluidized Bed Machine. The experimental results showed that coffee form and distributor hole angle are directly affected the fluidization behavior and SEC value. The RCC provided the lower pressure drop than PC for all distributor hole angle, leading to lower minimum fluidization velocity (Vmf) and SEC value. In term of distributor hole angle, the pressure drop was lowest for both RCC and PC when using the distributor hole angle of $60^{\circ}$. This distributor hole angle also provided the lowest in Vmf and SEC values. These results can be used for applying the coffee drying using the fluidized bed dryer in the coffee industry and Small and Medium Enterprises (SMEs).

\section{Acknowledgement}

The authors express the sincere appreciation to King Mongkut's Institute of Technology Ladkrabang, Prince of Chumphon Campus, Chumphon for providing the equipment for the experiment.

\section{References}

[1] Nawarat Pokeeree, Savitree Rangsipaht, and Patcharawadee Sriboonruang. "Factors related to Robusta coffee production of farmers in rubror sub-district, Tha Sae district, Chumphon province." King Mongkut's Agricultural Journal 36, no. 2 (2018): 43-52.

[2] Juliano S. Ribeiro, Terezinha J. Salva, and Márcia M.C. Ferreira. "Chemometric studies for quality control of processed Brazilian coffees using Drifts." Journal of Food Quality 33, (2010): $212-227$. https://doi.org/10.1111/i.1745-4557.2010.00309.x

[3] Payel Ghosh, and N. Venkatachalapathy. "Processing and drying of coffee - A review." International Journal of Engineering Research and Technology 3, No. 12 (2014): 784-794.

[4] Nilnont W, Thepa S, janjai S, Kasayapanand N, Thamrongmas C, and Bala BK. "Finite element simulation for coffee drying." Food and Bioproducts processing 90, (2012): 341-350. https://doi.org/10.1016/i.fbp.2011.06.007

[5] Sakchai Dondee, Naret Meeso, Somchart Soponronnarit, and Sirithon Siriamornpun. "Reducing cracking and breakage of soybean grains under combinednear-infrared radiation and fluidized-bed drying." Journal of Food Engineering 104, No. 1 (2011): 6-13. https://doi.org/10.1016/i.jfoodeng.2010.11.018

[6] Thatchapol Chungcharoen, Somkiat Prachayawarakorn, Patcharee Tungtrakul, and Somchart Soponronnarit. "Quality attributes of germinated high amylose and waxy rices in superheated steam and hot air dryings." Drying Technology 33, (2015): 876-885. https://doi.org/10.1080/07373937.2014.995304

[7] Naruebodee Srisang, Chairat Phetkeri, and Panya Daungvilailux. "Germinated cereals drying using hot air fluidization technique combined with halogen lamp." International Journal of Advances in Science, Engineering and Technology 4, No. 3 (2016): 154-159.

[8] Thatchapol Chungcharoen, Somkiat Prachayawarakorn, Somchart Soponronnarit, and Patcharee Tungtrakul. "Effect of drying temperature on drying characteristics and quality of germinated rices prepared from paddy and brown rice." Drying Technology 30, (2012): 1844-1853. https://doi.org/10.1080/07373937.2012.692744

[9] Md Insiat Islam Rabby, Siti Ujila Masuri, Ahmad Syakir Fariz Samsul Kamal, Zulkiflle Leman, Abdul Aziz Hairuddin, and Nuraini Abdul Aziz. "Flow characteristics of disk bypass pipeline inspection gauge (PIG) in natural gas pipelines using computational fluid dynamics." CFD Letters 13, no. 4 (2021): 11-37. https://doi.org/10.37934/cfdl.13.4.1137

[10] Nguyen Minh Phu, Pham Ba Thao, and Duong Cong Truyen. "Heat and fluid flow characteristics of nanofluid in a channel baffled opposite to the heated wall." CFD Letters 13, no. 1 (2021): 33-44. https://doi.org/10.37934/cfdl.13.1.3344

[11] DavidEscudero, and Theodore J. Heindel. "Minimum fluidization velocity in a 3D fluidized bed modified with an acoustic field." Chemical Engineering Journal 231, (2013): 68-75. https://doi.org/10.1016/j.cej.2013.07.011

[12] Waqar Ali Khan, Usman Asghar, and Imran Shamshad. "Effect of initial static bed height and liquid superficial velocity on the minimum fluidization velocity (Umf) and pressure drop for the bed of semolina particles in liquidsolid fluidization." Journal of Chemical Engineering \& Process Technology 7, No. 5 (2016): 100312. 
[13] Sau D.C., Mohanty S., and Biswal K.C. "Minimum fluidization velocities and maximum bed pressure drops for gassolid tapered fluidized beds." Chemical Engineering Journal 132, No. 1-3 (2007): 151-157. https://doi.org/10.1016/i.cej.2007.01.036

[14] Lifeng Zhang, Jiangtian Hou, Xiaotao T. Bi, John R. Grace, Travis Janke, and Claudio Arato. "Fluidization characteristics and charging behavior of fly ash in a vibro-fluidized bed." Powder Technology 215-216, (2012): 235241. https://doi.org/10.1016/i.powtec.2011.10.005

[15] Mayor L., Moreira R., and Sereno A.M. "Shrinkage, density, porosity and shape changes during dehydration of pumpkin (Cucurbita pepo L.) fruits." Journal of Food Engineering 103, (2011): $29-37$. https://doi.org/10.1016/i.jfoodeng.2010.08.031

[16] Mulet A., Garcia-Reverter J., Bon J., and Berna A. "Effect of shape on potato and cauliflower shrinkage during drying." Drying Technology 18, No. 6 (2000): 1201-1219. https://doi.org/10.1080/07373930008917772

[17] Bram J. Ramakers, Ronny de Ridder, and Piet J.A.M. Kerkhof. "Fluidiazation behavior of wood/sand mixtures." Proceedings of the 14th International Drying Symposium, (2014): 1337-1344.

[18] Zhu Zhiping, Na Yongjie, and Lu Qinggang. "Effect of pressure on minimum fluidization velocity." Journal of Thermal Science 16, No.3 (2007): 264-269. https://doi.org/10.1007/s11630-007-0264-2

[19] Nidal Hilal, Ghannam M.T., and Anabtawi M.Z. "Effect of bed diameter, distrubutor and inserts on minimum fluidization velocity." Chemical Engineering Technology 24, No. 2 (2001): 161-165. https://doi.org/10.1002/15214125(200102)24:2<161::AID-CEAT161>3.0.CO;2-S 